\title{
ERRATUM
}

\section{Kinetochore-microtubule error correction is driven by differentially regulated interaction modes}

\section{Maria Kalantzaki, Etsushi Kitamura, Tongli Zhang, Akihisa Mino, Béla Novák and Tomoyuki U. Tanaka}

Nat. Cell Biol. 16, http://dx.doi.org/10.1038/ncb3128 (2015); published online 9 March 2015; corrected online 11 March 2015

In the version of this Article originally published online, the lines connecting the data points were missing from the chart on the left of Fig. 8c; the correct graph is shown below. This has been corrected in all versions of the Article.

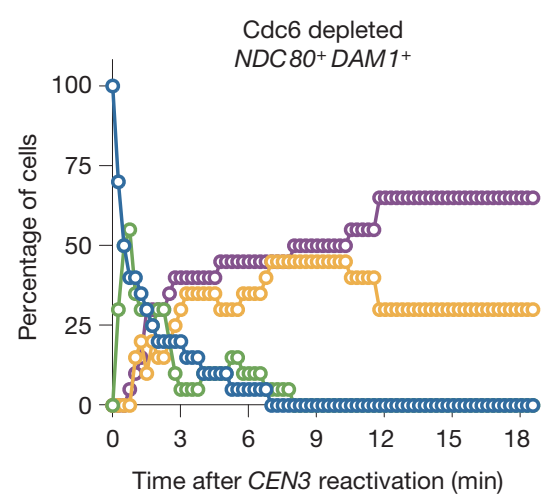

